\title{
VEGETARIAN DIET AND BREAST CANCER RISK: WHAT IS THE RELATION?
}

Jordana M. Oliveira', Larissa F. Almeida', Lucas F. S. Pereira', Sarah B. D. Carrijo', Gustavo M. Faria², Tulio R. Pimenta², Cesar A. S. T. Vilanova-Costa ${ }^{3}$, Antonio M. T. C. Silva ${ }^{1}$

'Escola de Ciências Médicas, Farmacêuticas e Biomédicas, Pontifícia Universidade Católica de Goiás - Goiânia (GO), Brazil. ²Universidade de Uberaba - Uberaba (MG), Brazil.

${ }^{3}$ Laboratório de Biologia Tumoral, Hospital Araújo Jorge, Associação de Combate ao Câncer em Goiás - Goiânia (GO), Brazil.

Objectives: The present study investigates the association between vegetarian diet ingestion and the risk of developing breast cancer. Methodology: This is a literature review realized through the search of scientific articles in the PubMed, Lilacs, and SciELO databases, from October 2018 to March 2019. Results: Of 6 studies evaluated on the present work, 3 articles (50\%) reached the decision that there is an inverse relationship between vegetable and fruit consumption and the incidence of breast cancer, demonstrating that vegetarianism would rather be a protective factor against the development of this type of cancer. Studies have indicated that many natural products such as soybeans, citrus fruits, cereals, and cruciferous vegetables, the basis of a vegetarian diet, can affect the installation and progression of breast cancer. Among the anti-breast cancer effects of this type of dietary pattern are the negative regulation of the expression and activity of estrogen alpha receptors, as well as the inhibition of the proliferation, migration, metastasis, and angiogenesis of cancer cells. Moreover, such foods still help to sensitize tumor cells to radio and chemotherapy. However, not all studies have reached the same conclusion: the other 3 articles searched identified that lifelong exposure to a vegetarian diet appears to have little or no effect on the risk of breast cancer. Conclusion: On the face of such dichotomized results, more studies are needed to arrive at the decision that a vegetarian diet decreases or does not change the risk of developing breast cancer. Thus, the vegetarian diet may or may not be indicated for the prevention of breast cancer. 